\title{
Attenuation Law of Train-Induced Vibration Response of Subgrade in Beijing-Harbin Railway
}

\author{
Ziyu Wang $\mathbb{D},{ }^{1,2}$ Xianzhang Ling $\mathbb{D}^{2},{ }^{2}$ Lina Wang $\mathbb{D}{ }^{3,4}$ and Yingying Zhao ${ }^{5}$ \\ ${ }^{1}$ Hainan Tropical Ocean University, School of Ecological Environment, Sanya, Hainan 572022, China \\ ${ }^{2}$ School of Civil Engineering, Harbin Institute of Technology, Harbin, Heilongjiang 150090, China \\ ${ }^{3}$ PowerChina Kunming Engineering Corporation Limited, Kunming, Yunnan 650051, China \\ ${ }^{4}$ College of Civil and Architectural Engineering, Yunnan Agricultural University, Kunming, Yunnan 650201, China \\ ${ }^{5}$ School of Civil Engineering, Southeast University, Nanjing, Jiangsu 211189, China \\ Correspondence should be addressed to Lina Wang; 2013049@ynau.edu.cn
}

Received 25 April 2021; Accepted 29 June 2021; Published 8 July 2021

Academic Editor: Alvaro Cunha

Copyright (c) 2021 Ziyu Wang et al. This is an open access article distributed under the Creative Commons Attribution License, which permits unrestricted use, distribution, and reproduction in any medium, provided the original work is properly cited.

\begin{abstract}
To investigate environmental vibration in the case of railway subgrade in seasonally frozen regions, field experiments were conducted on the Beijing-Harbin railway subgrade of China in autumn and winter. Vibration acceleration and vibration level attenuation law were analysed based on monitoring results. Accordingly, the influence of the subgrade freeze-thaw states, vehicle load, train formation, and running speed on the subgrade surface environmental vibration was analysed. The vibration response of the subgrade decreased with an increase in the distance from the track. The attenuation curve of the vibration acceleration can be fitted using the negative exponential function, and the attenuation curve of the vibration level can be fitted using the linear function. Additionally, the subgrade vibration response during the frozen period was greater than that during the unfrozen period owing to increased strength and rigidity and decreased damping ratio after subgrade freezing, which increased the vibration response. Moreover, the vibration intensity of the subgrade increased with increase in the vehicle load and formation and decreased with an increase in the driving speed within a particular speed range. The findings of this study provide an objective basis for railway subgrade design and disaster assessment in cold regions of China.
\end{abstract}

\section{Introduction}

In seasonally frozen regions, periodic freeze-thaw cycles and train vibrations are the main causes of railway subgrade degradation. Scholars at home and abroad have investigated the vibration response of the subgrade in unfrozen regions and have gained many research achievements. Based on the finite element method, a three-dimensional (3D) dynamic analysis model of the subgrade has been established to predict its vibration response [1-4]. As a basic method, field monitoring has been employed to study the dynamic characteristics of the subgrade. Such research includes mainly the time-domain amplitude distribution of the dynamic response indices of stress and vibration acceleration as well as spectrum analysis. Takemiya and Bian [5] analysed the test data of the Shinkansen line in Tokaido, Japan, and found that the pulse vibration generated by high-speed trains on the subgrade corresponded to the wheelset spacing. They reported that the subgrade vibration characteristics can be predicted according to the wheelset spacing and the number of vehicles. Xia [6] tested the environmental vibrations caused by running trains, studied the vibration of the surrounding buildings and the environmental noise caused by the traffic load, and obtained the temporal amplitude distribution mechanism of dynamic response indices, including dynamic stress and acceleration. Many researchers [7-10] have monitored the vibration acceleration of subgrade vibrations of the Qinhuangdao-Shenyang passenger-dedicated line under different speeds and obtained the basic ground vibration and acceleration 
attenuation mechanisms generated by a high-speed wheelrail train. Qu et al. [11] conducted field testing on the subgrade vibration of high-speed Wuhan-Guangzhou railway and obtained the distribution mechanism of dynamic response and the natural frequency of the subgrade in the test section. Zheng et al. [12] studied the vibration characteristics of the embankment of expansive soil with various stiffness indices on the Hefei-Nanjing express passenger-dedicated line. Bin et al. [13] studied the influence of the train type and speed on the ground vibration speed by monitoring the train vibration in a particular location in Nanjing and discussed the frequency spectrum characteristics and attenuation mechanism of the ground vibration speed. Zhi-zhong et al. [14] conducted monitoring and comparative analysis on the ground temperature characteristics of a block stone subgrade and an ordinary subgrade in a test section of the Qinghai-Tibet railway. Fu-jun et al. [15] analysed the ground temperature development process, thermal stability, and secondary freeze-thaw disasters in the permafrost subgrade of the Qinghai-Tibet railway via the on-site monitoring of the frozen soil subgrade and evaluated the differences in subgrade vibration attenuation between warm and cold seasons. Yahu et al. [16] monitored the deformation of railway subgrade in seasonally frozen soil and analysed the causes of frost damage.

Considering the aforementioned studies, the aim of the present paper is to investigate the vibration response of the subgrade in a typical seasonally frozen region and analyse its attenuation mechanism based on field monitoring. Factors, such as the subgrade influencing the freezing state, train formation, and vehicle load and speed, are shown to be essential in the analysis.

\section{Field Monitoring Overview}

Harbin is a large city in northeastern China and exhibits the highest latitude and lowest temperature. This city shows a midtemperate continental monsoon climate with four distinct seasons including long winters and short summers. The highest temperature in summer exceeds $37^{\circ} \mathrm{C}$, the lowest temperature in winter is below $-35^{\circ} \mathrm{C}$, and the maximum freezing depth is approximately $1.8-2 \mathrm{~m}$. Figure 1 shows the field monitoring results.

In this analysis, two sections were selected for monitoring the frozen and unfrozen periods. The monitoring sections comprised the k1229+ 095 sections of the Wanggang to the Shuangcheng section of the Beijing-Harbin railway. Eight measuring points, namely, rail $(B 1)$, sleeper $(B 2)$, shoulder (B3), embankment (B4 and B5), slope angle (B6), and site (B7 and $B 8$ ) were selected for each monitoring section. Figure 2 shows the geometry, layout, and stratum structure of the monitoring sections. The 891-2 vibration metre developed by the Institute of Engineering Mechanics, State Seismological Bureau of China, was used as the monitoring instrument. The frequency band was $0.5-80 \mathrm{~Hz}$, and the vibration acceleration resolution was $1 \times 10^{-5}$. The INV306 signal acquisition and analysis system developed by the China Oriental Institute of Vibration and Noise Technology was used as the acquisition equipment.

\section{Monitoring Results}

The monitoring results include two typical vibration acceleration time histories during the frozen (winter) and unfrozen (autumn) periods. During these two periods, the vibration acceleration of different train types, speeds, and formations was monitored at the eight measuring points. More than 80 groups of data, including the data for passing trains, were monitored. Table 1 lists the effective acceleration values of each measuring point during the frozen and unfrozen periods. The effective value of the acceleration of a freight train with a large load was greater than that of a passenger train.

3.1. Vibration Acceleration Time-History Response. The vertical acceleration time-history curve of the B3-B8 measuring points for passenger train 1548 and a typical freight train in winter is shown in Figure 3, where the peak and trough of the acceleration appear in pairs. At the point near the centre of the line, the peak obviously corresponds to the passing time of the train wheel. At the point far from the centre of the line, the acceleration value was small, shown as the spindle type. The structural vibration caused by the passing train occurred from the track to the subgrade, and the vibration intensity obviously decreased after the train passed through the sleeper and ballast.

\subsection{Acceleration Effective Value and Level}

3.2.1. Define the Acceleration Value. According to the layout of acceleration sensors, the spatial coordinate direction was defined as follows. The vertical direction perpendicular to the track extension was the vertical direction ( $z$-direction). To study the variation mechanism and attenuation characteristics of the vibration acceleration response, the magnitude of the effective value of the vibration acceleration was defined. The z-directions were recorded as $\left|a_{z}\right|_{\text {val }}$ as follows:

$$
\left|a_{z}\right|_{\mathrm{val}}=\frac{1}{N} \sqrt{\sum_{j=1}^{N}\left|a_{z j}\right|^{2},} \quad(j=1,2,3 \ldots, N),
$$

where $a_{z j}$ is the $N^{\mathrm{st}}$ acceleration recorded in the corresponding direction as the train passes and $N$ is the number of acceleration records collected when the train passes.

3.2.2. Define the Vibration Level. For environmental vibration analysis, the vibration intensity is measured based on the acceleration vibration level $(\mathrm{dB})$. The vibration acceleration level is determined by calculating the logarithm of the ratio of the effective value of acceleration and the reference acceleration at the base 10 logarithm. The result is then multiplied by 20 , expressed in decibels as follows: 


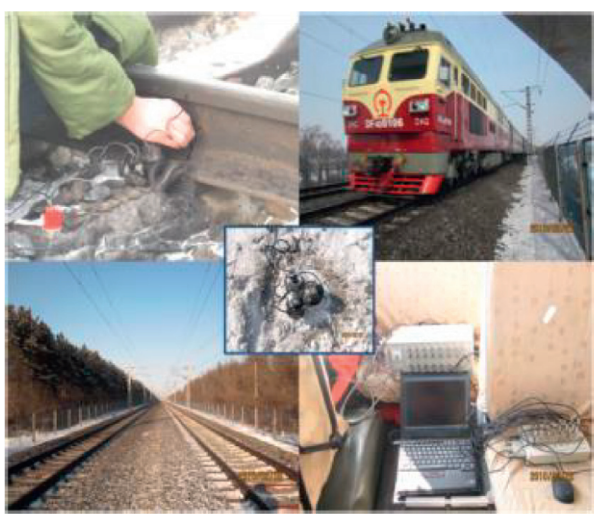

(a)

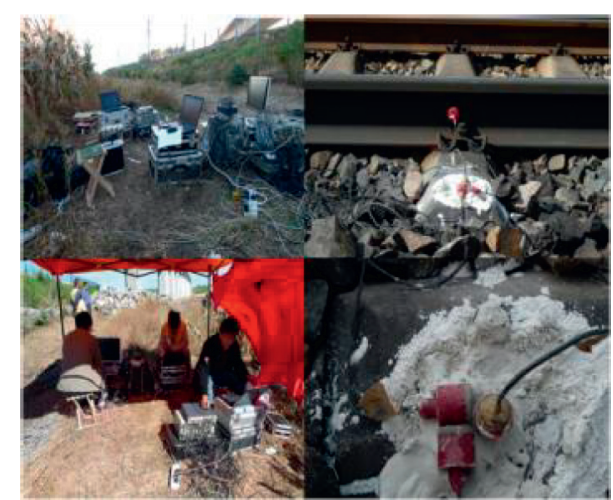

(b)

FIGURE 1: General conditions of field monitoring: (a) frozen period; (b) unfrozen period.
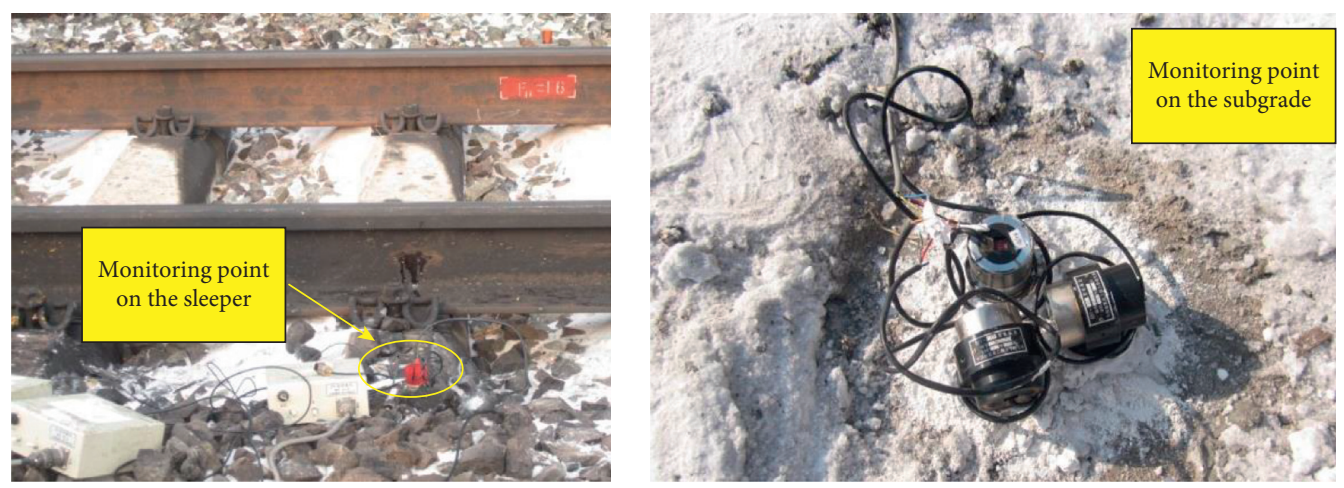

(a)

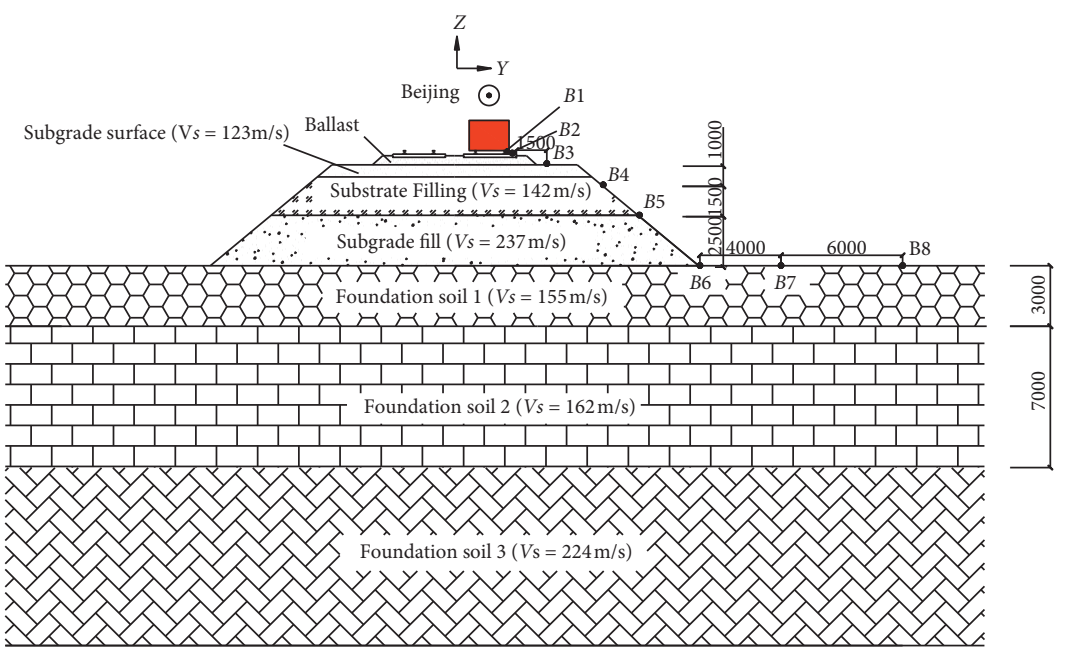

(b)

Figure 2: Geometry of monitoring section and layout of sensors in Beijing-Harbin railway.

$$
L_{a i}=20 \lg \left(\frac{a_{z}}{a_{0}}\right),
$$

where $a_{Z}$ is the vibration acceleration and $a_{0}$ is the acceleration reference value: $a_{0}=1 \times 10^{6} \mathrm{~m} / \mathrm{s}^{2}$. The direction parallel to the track line is defined as the direction perpendicular to the ground which is vertical ( $z$-direction).
Figures 4 and 5 show the attenuation mechanism of vibration response of each train at each measuring point during the unfrozen and frozen periods, respectively. As the distance from the track increased, the amplitude of each train decreased and the effective value of the acceleration essentially returned to zero at the horizontal distance of $15 \mathrm{~m}$ from the slope angle. Moreover, the effective value of the 
Table 1: Amplitude statistics of subgrade vibration acceleration from trains at the $\mathrm{k} 1229+135$ section of the Beijing-Harbin railway.

\begin{tabular}{|c|c|c|c|c|c|c|c|c|}
\hline Season & $\begin{array}{l}\text { Vehicle type and number } \\
\qquad\left|a_{z}\right|_{\text {val }}\end{array}$ & $\begin{array}{c}\text { Train frame } \\
\left|a_{z}\right|_{\text {val }}\end{array}$ & $\begin{array}{c}B 3 \\
\left|a_{z}\right|_{\mathrm{val}} \\
\end{array}$ & $\begin{array}{c}B 4 \\
\left|a_{z}\right|_{\text {val }}\end{array}$ & $\begin{array}{c}B 5 \\
\left|a_{z}\right|_{\mathrm{val}} \\
\end{array}$ & $\begin{array}{c}B 6 \\
\left|a_{z}\right|_{\mathrm{val}} \\
\end{array}$ & $B 7$ & $B 8$ \\
\hline \multirow{8}{*}{ Autumn } & Freight train 1 & - & 0.2425 & 0.0618 & 0.0383 & 0.0460 & 0.0173 & 0.0145 \\
\hline & Freight train 2 & - & 0.1599 & 0.0353 & 0.0267 & 0.0259 & 0.0136 & 0.0096 \\
\hline & Freight train 3 & - & 0.2017 & 0.0750 & 0.0496 & 0.0468 & 0.0199 & 0.0152 \\
\hline & Freight train 4 & - & 0.2547 & 0.0819 & 0.0480 & 0.0632 & 0.0239 & 0.0183 \\
\hline & Passenger train $\mathrm{K} 116$ & $1+17$ & 0.1879 & 0.0450 & 0.0266 & 0.0341 & 0.0140 & 0.0096 \\
\hline & Passenger train 1526 & $1+19$ & 0.2002 & 0.0550 & 0.0356 & 0.0430 & 0.0178 & 0.0135 \\
\hline & Passenger train K554 & $1+17$ & 0.1811 & 0.0462 & 0.0272 & 0.0363 & 0.0150 & 0.0096 \\
\hline & Motor train D26 & $1+7$ & 0.1641 & 0.0546 & 0.0396 & 0.0388 & 0.0143 & 0.0118 \\
\hline \multirow{19}{*}{ Winter } & Passenger train 1526 & $1+19$ & 0.2492 & 0.0357 & 0.0304 & 0.0146 & 0.0075 & 0.0054 \\
\hline & Passenger train 0578 & $1+18$ & 0.1777 & 0.0308 & 0.0262 & 0.0137 & 0.0068 & 0.0055 \\
\hline & Freight train 1 & $2+64$ & 0.3899 & 0.0669 & 0.0604 & 0.036 & 0.0133 & 0.0167 \\
\hline & Freight train 2 & $2+56$ & 0.3276 & 0.0653 & 0.0575 & 0.0319 & 0.0128 & 0.0148 \\
\hline & Freight train 3 & $2+68$ & 0.2585 & 0.0696 & 0.0656 & 0.0385 & 0.0144 & 0.0174 \\
\hline & Freight train 4 & $2+66$ & 0.2373 & 0.0669 & 0.0631 & 0.0354 & 0.0138 & 0.0167 \\
\hline & Passenger train K1026 & $1+17$ & 0.3239 & 0.0489 & 0.0423 & 0.0205 & 0.0098 & 0.0071 \\
\hline & Passenger train L1226 & $1+15$ & 0.327 & 0.0322 & 0.0315 & 0.0157 & 0.0079 & 0.0063 \\
\hline & Freight train 5 & $1+31$ & 0.2198 & 0.041 & 0.0398 & 0.0223 & 0.0082 & 0.0107 \\
\hline & Freight train 6 & $2+66$ & 0.2314 & 0.0724 & 0.0688 & 0.036 & 0.0138 & 0.0168 \\
\hline & Freight train 7 & $2+62$ & 0.2521 & 0.0618 & 0.0594 & 0.0312 & 0.0122 & 0.0151 \\
\hline & Passenger train $\mathrm{K} 40$ & $1+19$ & 0.167 & 0.0414 & 0.037 & 0.018 & 0.0084 & 0.0073 \\
\hline & Motor train D174 & $1+7$ & 0.1384 & 0.0403 & 0.0381 & 0.0231 & 0.0108 & 0.0115 \\
\hline & Passenger train 1548 & $1+19$ & 0.2303 & 0.0506 & 0.0449 & 0.0201 & 0.01 & 0.0077 \\
\hline & Freight train 8 & $1+41$ & 0.2261 & 0.0535 & 0.0498 & 0.0305 & 0.0097 & 0.015 \\
\hline & Passenger train 1326 & $1+19$ & 0.116 & 0.0431 & 0.0384 & 0.0201 & 0.0095 & 0.0079 \\
\hline & Passenger train K554 & $1+17$ & 0.2707 & 0.0444 & 0.0366 & 0.0178 & 0.0088 & 0.0072 \\
\hline & Passenger train L14 & $1+16$ & 0.264 & 0.0308 & 0.0265 & 0.014 & 0.0071 & 0.0055 \\
\hline & Freight train 9 & $2+60$ & 0.242 & 0.0599 & 0.0534 & 0.032 & 0.012 & 0.0153 \\
\hline
\end{tabular}

acceleration of the freight train with a large load was larger than that of the passenger train, and the acceleration amplitude of the freight train with a small load was smaller. The attenuation mechanism of acceleration of each train conformed to the negative exponential function; the attenuation fitting functions in the unfrozen and frozen periods were | $\left.a_{z}\right|_{\mathrm{val}}=0.3171 e^{-0.2516 x}$ and $0.4511 e^{-0.3226 x}$, respectively. The attenuation mechanism of the vibration level of each train conformed to the first-order function; the attenuation fitting functions in the unfrozen and frozen periods were $L_{a z}=-1.1917 \times x+104.0799$ and $-1.4223 \times x+105.0368$, respectively.

\section{Analysis of Influencing Factors}

4.1. Influence of Subgrade Freezing State on Vibration Response. For passenger train K554, the effective values of the acceleration at $\mathrm{B} 3$ during the frozen and unfrozen periods were 0.2707 and $0.1811 \mathrm{~m} / \mathrm{s}^{2}$, respectively. As shown in Figure 6(a), the acceleration vibration intensity of the same train during the frozen period was slightly higher than that during the unfrozen period, attributed to the increase in the strength and stiffness of the frozen layer as well as the acceleration amplitude during the frozen period. These results are consistent with the monitoring results of the subgrade vibration acceleration for the Daqing-Harbin railway [17]. As shown in Figure 6(b), the acceleration vibration level decreased from $110 \mathrm{~dB}$ to $80 \mathrm{~dB}$ at $B 3-B 8$ and the attenuation mechanism was close to linear attenuation.

4.2. Influence of Train Formation and Load. The acceleration amplitude, vibration level, and attenuation mechanism of typical freight cars, motor cars, and express buses were analysed. Figure 7 shows that the vibration acceleration amplitude and vibration level of the freight train were slightly larger than those of the passenger cars at all measuring points. This occurred because the load capacity and train formation of freight cars are larger than those of passenger cars; therefore, the vehicle load and formation have obvious influences on the vibration response. According to the attenuation mechanism, the acceleration vibration level decreased from $110 \mathrm{~dB}$ to $80 \mathrm{~dB}$ at $B 3-B 8$ and the attenuation mechanism was close to linear attenuation. The vibration acceleration attenuated rapidly $0-5 \mathrm{~m}$ from the track centre, slowly decreased $5-15 \mathrm{~m}$ from the track centre, and returned to zero 15-20 m from the track centre.

4.3. Influence of Vehicle Speed on Vibration Response. The influence of the vehicle speed on the subgrade vibration response was analysed by comparing the results of passenger trains 1526 and K40 with $1+19$ marshalling and travel speeds of 5 and $100 \mathrm{~km} / \mathrm{h}$, respectively. Figure 8 


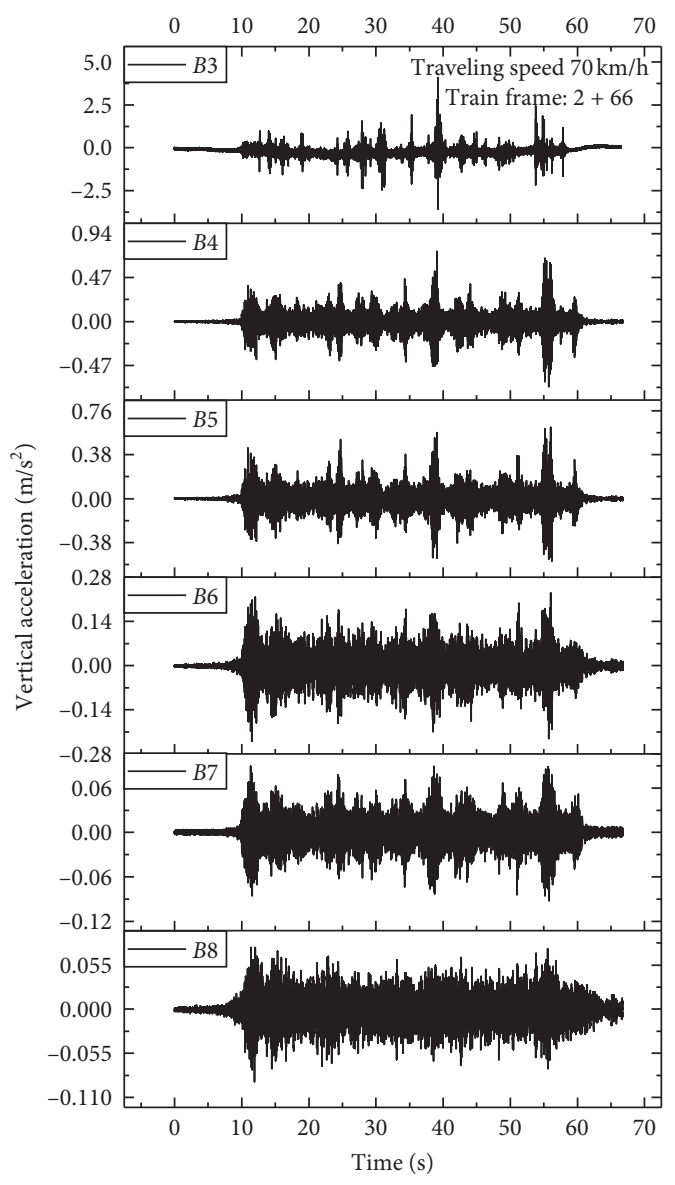

(a)

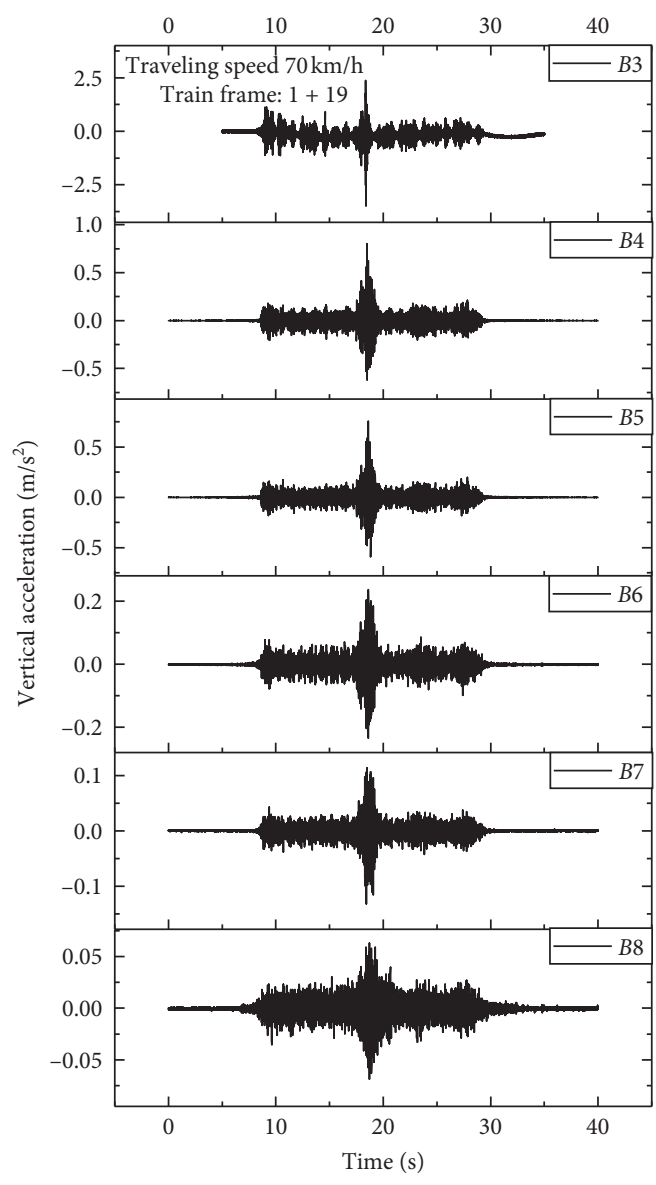

(b)

Figure 3: Acceleration time-history curves: (a) freight train 3; (b) passenger train 1548.

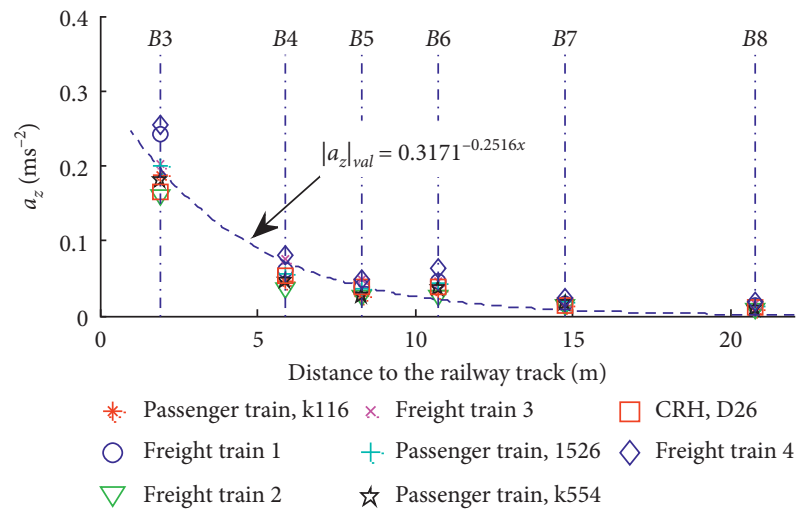

(a)

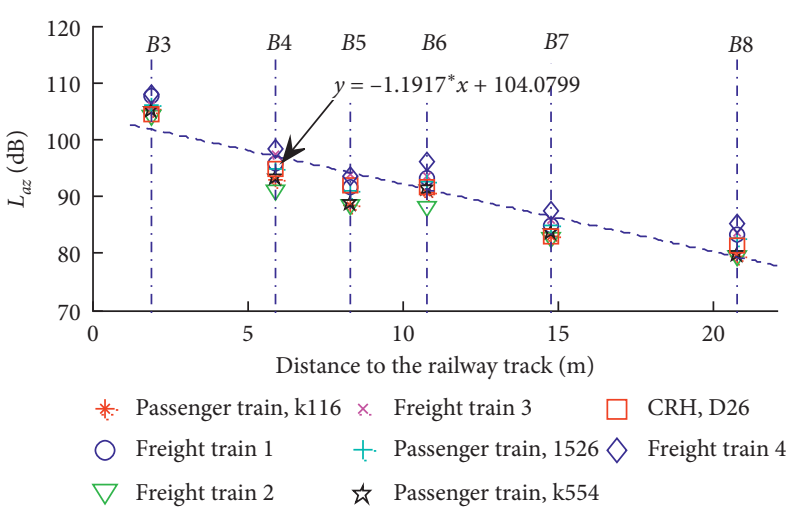

(b)

FIGURE 4: Fitting curve of the vibration level attenuation mechanism in the unfrozen period: (a) effective value of acceleration and (b) acceleration level.

shows that the effective values of vibration acceleration of these trains at $B 3$ were 0.2492 and $0.167 \mathrm{~m} / \mathrm{s}^{2}$, respectively, and the vibration levels were 105.2 and $107.8 \mathrm{~Hz}$, respectively. Thus, the vibration response of the subgrade decreased with an increase in the vehicle speed within this speed range. 

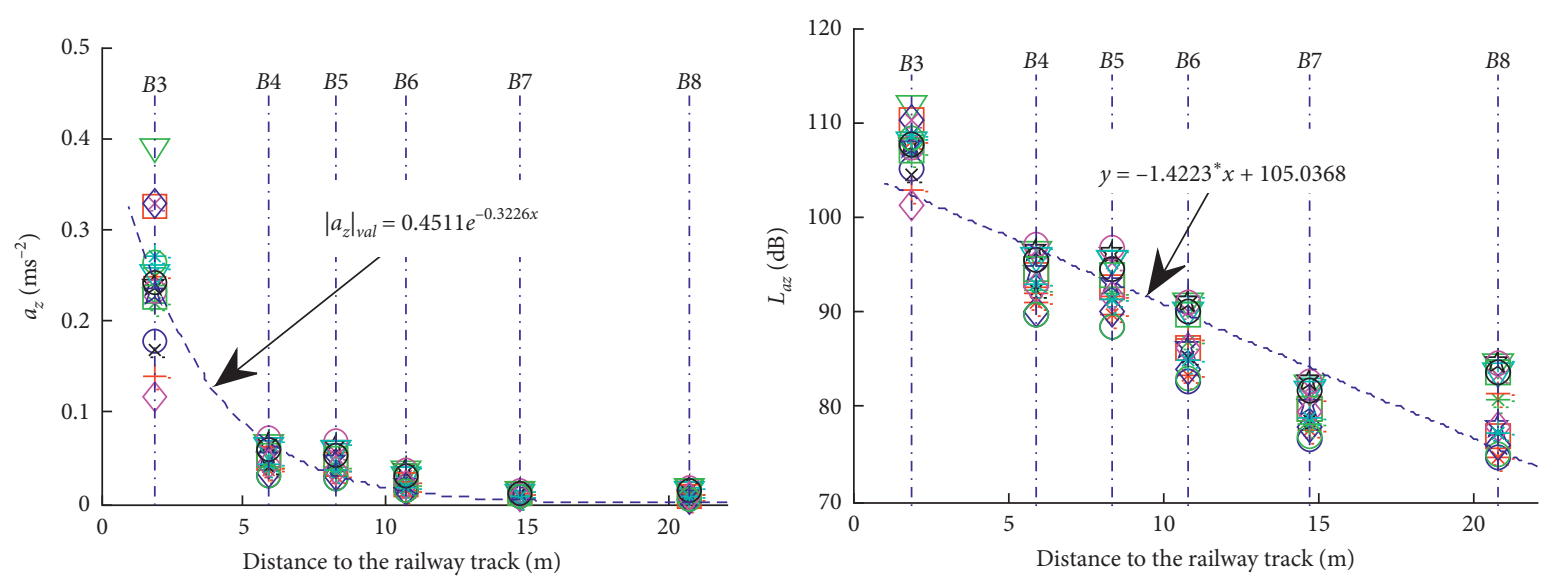

\begin{tabular}{|c|c|}
\hline Passenger train, 1526 & $\nabla$ Freight train 7 \\
\hline Passenger train, 0578 & $x \quad$ Passenger train, k40 \\
\hline Freight train 1 & $+\mathrm{CRH}, \mathrm{D} 174$ \\
\hline Freight train 2 & 放 Passenger train, 1548 \\
\hline Freight train 3 & $\square$ Freight train 8 \\
\hline Freight train 4 & $\diamond$ Passenger train, $\mathrm{k} 40$ \\
\hline Passenger train, k1026 & *. Passenger train, k554 \\
\hline Passenger train, L1226 & Passenger train, L14 \\
\hline Freight train 5 & Freight train 9 \\
\hline Freight train 6 & \\
\hline
\end{tabular}

(a)
*. Passenger train, 1526
$\nabla$ Freight train 7
$\bigcirc$ Passenger train, 0578
x. Passenger train, $\mathrm{k} 40$
$\nabla$ Freight train 1
+ CRH, D174
$x$ Freight train 2
+ Freight train 3
次 Freight train 4
$\square$ Passenger train, k1026
$\diamond$ Passenger train, L1226
*. Freight train 5
Freight train 6
i Passenger train, 1548
$\square$ Freight train 8
$\diamond$ Passenger train, 1326
*. Passenger train, k554
Passenger train, L14
Freight train 9

(b)

FIGURE 5: Fitting curve of the vibration level attenuation mechanism in the frozen period: (a) effective value of acceleration and (b) acceleration level.

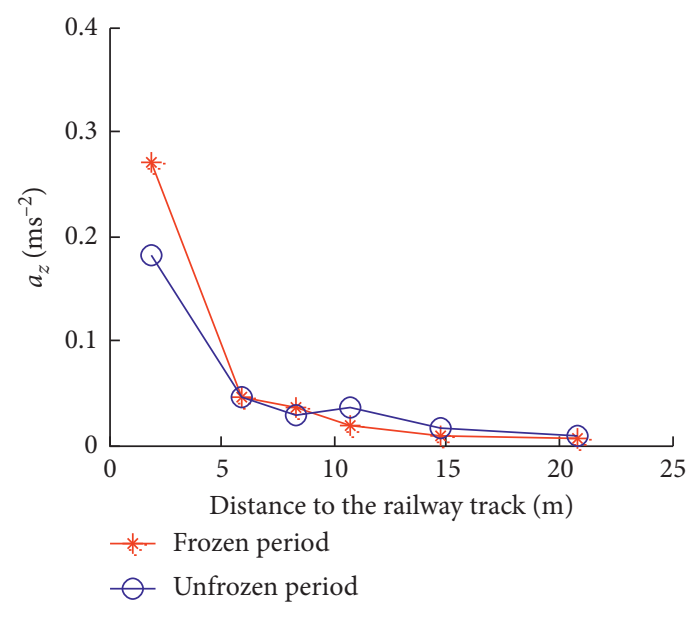

(a)

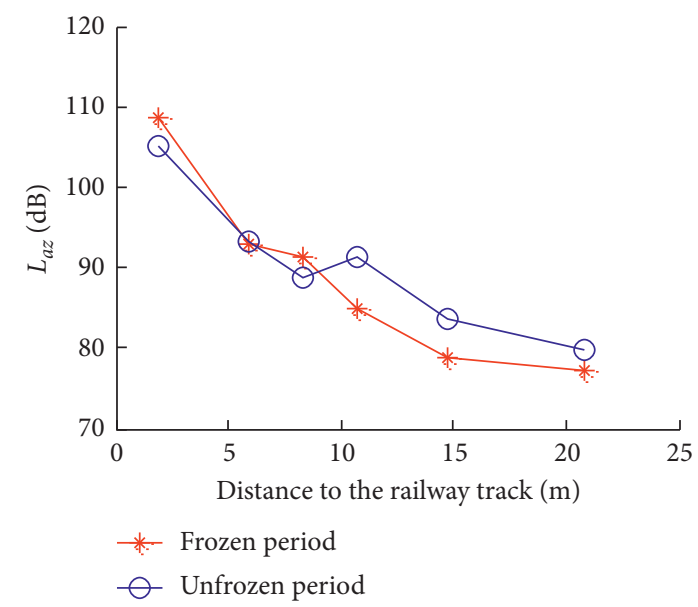

(b)

FIGURE 6: Attenuation mechanism of the vibration response during different frozen periods (passenger train K554): (a) vibration acceleration; (b) vibration level. 


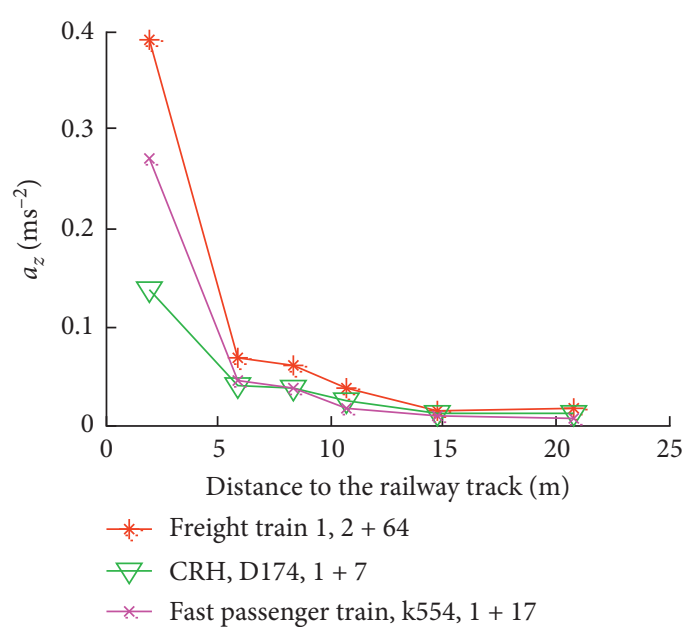

(a)

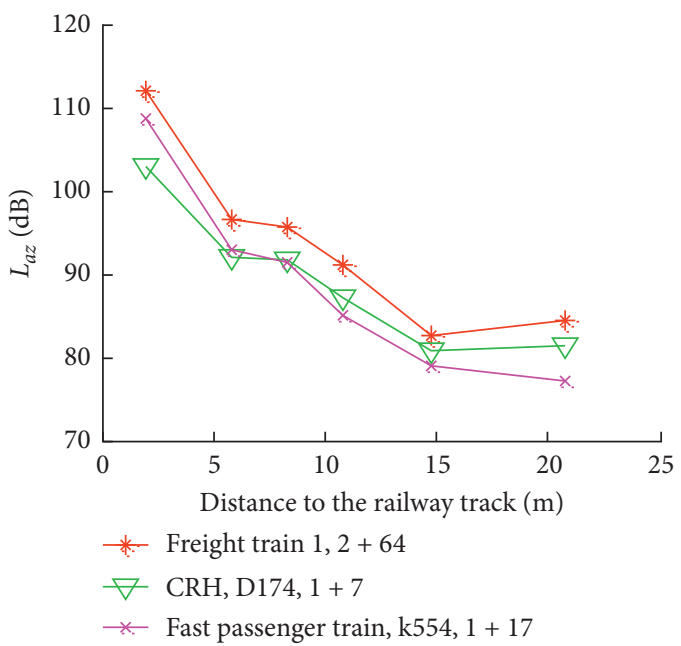

(b)

FIGURE 7: Attenuation mechanism of the vibration response for different train types: (a) vibration acceleration and (b) vibration level.

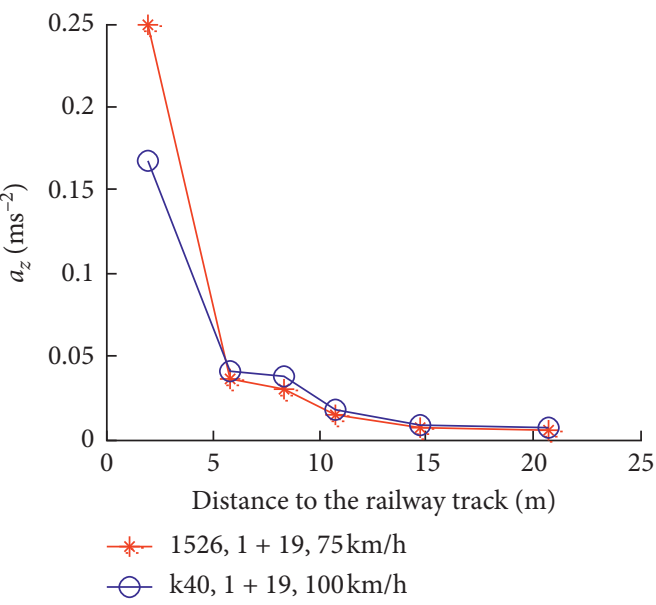

(a)

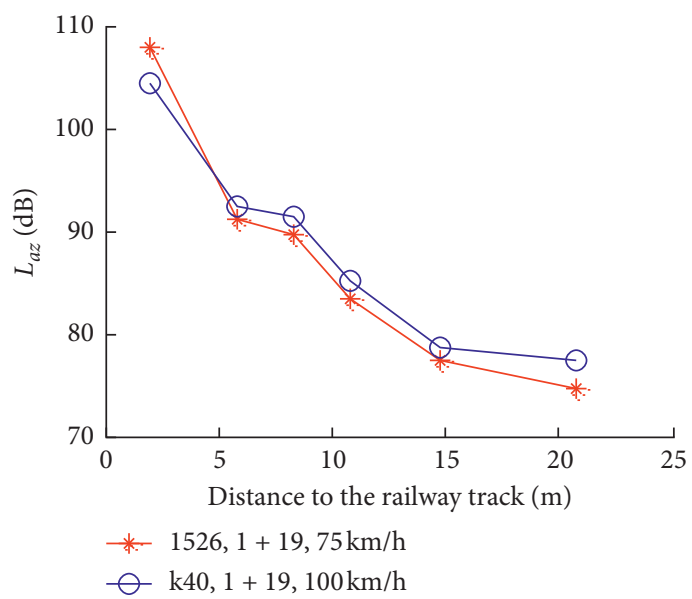

(b)

FIGURE 8: Attenuation mechanism of the vibration response at driving speeds during the frozen period: (a) vibration acceleration; (b) vibration level.

\section{Conclusion}

In this study, the vibration acceleration in the case of the Beijing-Harbin railway subgrade in a typical seasonally frozen region was monitored during frozen and unfrozen periods. Based on the monitoring results, the vibration acceleration and vibration level attenuation mechanism were analysed, along with the influencing factors of the vibration response. The results are summarised as follows:

(1) The attenuation mechanism of the vibration response was analysed. The vibration response of the subgrade in the seasonally frozen region decreased with an increase in the distance from the track. The attenuation curve of the effective value of the vibration acceleration was fitted using the negative exponential function $\left|a_{z}\right|_{\text {val }}=A * \exp (-B x)$, and the attenuation mechanism of the vibration level was fitted using the linear function $L=B * x+A$, where $A$ and $B$ represent the initial value and attenuation rate of the vibration response, respectively.

(2) Compared with the monitoring results of the subgrade vibration response in different seasons, the vibration intensity of the subgrade during the frozen period was greater than that during the unfrozen period when the same train passed. This is attributed to the formation of ice in the subgrade during winter, which increases the subgrade strength and stiffness and decreases the damping ratio, subsequently increasing the vibration response.

(3) The vibration response of the subgrade was affected by the vehicle load, vehicle formation, and running speed. Under similar conditions, a greater train formation and load signified a greater subgrade vibration response. Within a particular speed range, 
the subgrade vibration response decreased with an increase in the driving speed.

\section{Data Availability}

The data are obtained by on-site monitoring, and the original data can be obtained through e-mail from the first author.

\section{Conflicts of Interest}

The authors declare that they have no conflicts of interest.

\section{Acknowledgments}

This work was financially supported by the Key Research and Development Projects in Hainan Province (grant no. ZDYF2017100), the Yunnan Science and Technology Department Basic Research Project of China (grant no. 202101AT070253), and the State Key Laboratory Project of China (grant nos. SKLFSE201907 and KF2020-12).

\section{References}

[1] X. Fuchun and Z. Jianmin, "Attenuations of acceleration spectra of high-speed railway embankment subjected to moving loads," Rock and Soil Mechanics, vol. 36, no. Supp. 1, pp. 445-451, 2015.

[2] J. Fernández Ruiz, P. Alves Costa, R. Calçada, L. E. Medina Rodríguez, and A. Colaço, "Study of ground vibrations induced by railway traffic in a 3D FEM model formulated in the time domain: experimental validation," Structure and Infrastructure Engineering, vol. 13, no. 5, pp. 652-664, 2017.

[3] L. Wenjie, M. Huijie, L. Wuming et al., "Numerical analysis of dynamic stress response characteristics of subgrade bed," Journal of the Railway Society, vol. 39, no. 12, pp. 108-117, 2017.

[4] L. Wuming, N. Rusong, L. Wenjie et al., "Random distribution characteristics of peak dynamic stress on subgrade surface of heavy haul railway," Rock and Soil Mechanics, vol. 40, no. 4, pp. 1603-1613, 2019.

[5] H. Takemiya and X. Bian, "Substructure simulation of inhomogeneous track and layered ground dynamic interaction under train passage," Journal of Engineering Mechanics, vol. 131, no. 7, pp. 699-711, 2005.

[6] H. Xia, Traffic Induced Environmental Vibrations and Controls, Science Press, Beijing, China, 2010.

[7] G. Y. Gao, Z. Y. Li, S. J. Feng et al., "Experimental results and numerical predictions of ground vibration induced by highspeed train running on Qinghuangdao-Shengyang railway," Rock and Soil Mechanics, vol. 28, no. 9, pp. 1817-1822, 2007.

[8] W. M. Zhai, Vehicle-Track Coupling Dynamics, Science Press, Beijing, China, 2007.

[9] Y. M. Sun, Ground Vibration Due to Railway Traffic and Vibration Isolation by Piles in Row, Tongji University, Shanghai, China, 2003.

[10] N. Zhi-hong, L. Liang, L. Bao-chen et al., "Testing and analysis on vibration of subgrade for Qinghuangdao-Shenyang railway," Chinese Journal of Rock Mechanics and Engineering, vol. 24, no. 6, pp. 1067-1071, 2005.

[11] C. Z. Qu, Y. H. Wang, L. M. Wei, and Z. G. Guo, "In-situ test and analysis of vibration of subgrade for Wuhan-Guangzhou high-speed railway," Rock and Soil Mechanics, vol. 33, no. 5, pp. 1451-1456, 2012.

[12] D. W. Zheng, B. L. Wang, and Z. H. S Huang, "Study on vibration character of expansive soil embankments with different rigidities along Hefei-Nanjing rapid railway," Chinese Journal of Rock Mechanics and Engineering, vol. 25, no. z2, pp. 4204-4208, 2006.

[13] C. Bin, C. Guo-xing, Z. Ding-hua et al., "Experimental study of ground vibration caused by rail transit," Journal of Disaster Prevention and Mitigation Engineering, vol. 27, no. 3, pp. 312-317, 2007.

[14] S. Zhi-zhong, W. Ma, and L. Dong-qing, "Ground temperature characteristics of block stone embankment and traditional embankment at Beiluhe along Qinghai-Tibet railway," Chinese Journal of Geotechnical Engineering, vol. 30, no. 2, pp. 303-308, 2008.

[15] N. Fu-jun, W. Ma, and W. Qing-bai, "Thermal stability of roadbeds of the Qinghai-Tibet railway in permafrost regions and the main freezing-thawing hazards," Journal of Earth Sciences and Environment, vol. 33, no. 2, pp. 196-206, 2011.

[16] T. Yahu, W. Liguang, and L. Jiankun, "Monitoring of roadbed deformation of railway and freezing hazard analysis in seasonal frozen ground," Railway Engineering, vol. 7, pp. 104107, 2010, in Chinese.

[17] Z. Wang, Dynamic Response Characteristics and Permanent Deformation of Subgrade Induced by Train Load in Seasonally Deep Frozen Region, pp. 106-108, Harbin Institute of Technology, Harbin, China, 2015. 